Article

\title{
The Finite Element Analysis for Concrete Filled Steel Columns under Blast Load
}

\author{
Fereydoon Omidinasab ${ }^{1}$, Peyman Beiranvand ${ }^{1, *}$, Saeideh Sadeghi Golmakani ${ }^{2}$ and Mohammad \\ Zarei $^{3}$ \\ 1 Department of Civil Engineering, Lorestan University, Khorram abad, Iran; omidinasab@gmail.com \\ 2 Department of Civil Engineering, Ferdowsi University of Mashhad, Mashhad 9177948974, Iran; \\ saeideh_sa1368@yahoo.com \\ 3 Department of Civil Engineering, Imam Khomeini International University, Qazvin 3414916818, Iran; \\ mohammadzarei959@yahoo.com \\ * Correspondence: peyman51471366@gmail.com; Tel.: (+98)-937-8651620
}

\begin{abstract}
Concrete-filled steel columns have been extensively used in the world due to having all suitable characteristics of concrete and steel, more ductility, increasing concrete confinement using steel wall, large energy-absorption capacity and appropriate fire behavior. In present paper, concrete-filled steel square columns have been simulated under the influence of blast load using ABAQUS software. These responses will be compared for scaled distances based on the distance to source and weight of explosive material. As result, it can be seen that although concrete deformation has been restricted using steel tube, but inner layer of concrete has been seriously damaged and column displacement will be decreased by increasing scaled distance. We also concluded that concrete-filled steel columns have high ductility and blast resistance.
\end{abstract}

Keywords: blast load; concrete-filled steel columns; finite element analysis

\section{Introduction}

Nowadays concrete-filled steel structures have been extensively used all around the world because of being more economic, less deformation in lateral loading and reducing the dimensions of the section with the same load capacity, less weight and as result having all suitable characteristics of concrete and steel. These types of sections have also ductility, larger energy absorption capacity and power and ultimately fir resistance. Explosion is the result of sudden release of energy that can be as combusting gases, nuclear explosion or as result of different types of bomb. TNT is usually used as a reference for determining explosion power. Of main characteristics of explosion that leads to pushing force on structure, randomness of explosive situation, forces' dynamicity and transience of forces and low impact (between a few milliseconds to several seconds) can be mentioned. When there is an explosion, energy is suddenly released. The effect of releasing this energy can be divided into two parts of thermal radiations and wave propagation in land and air that in current paper, only the first section is investigated. Steel is a material with high thermal lead however when it is affected by fire, its resistance will be rapidly decreased. Blast responses are usually more noticeable for vital structures and protection ones. By loading concrete-filled steel columns, restricted concrete prevents local buckling to the inside steel wall because there will be restriction mood in concrete and therefore it will be pressured triaxially and member's rapture will be deformed from brittle state to plastics compared to concrete columns.

Of researches that have been implemented in this case, the research of Fuji Kura et al [1] can be mentioned that has experimentally investigated the behavior of constructed bridges made of concrete-filled steel section under the influence of blast loads. Marson and Bruneau [2] also investigated the connection of foundation to concrete filled steel columns under impact load with the ratio of diameter with a thickness of 34 to 64 by experiments according to figure 1 . The results show that considering cyclic curves, these types of sections have excellent ductility. 


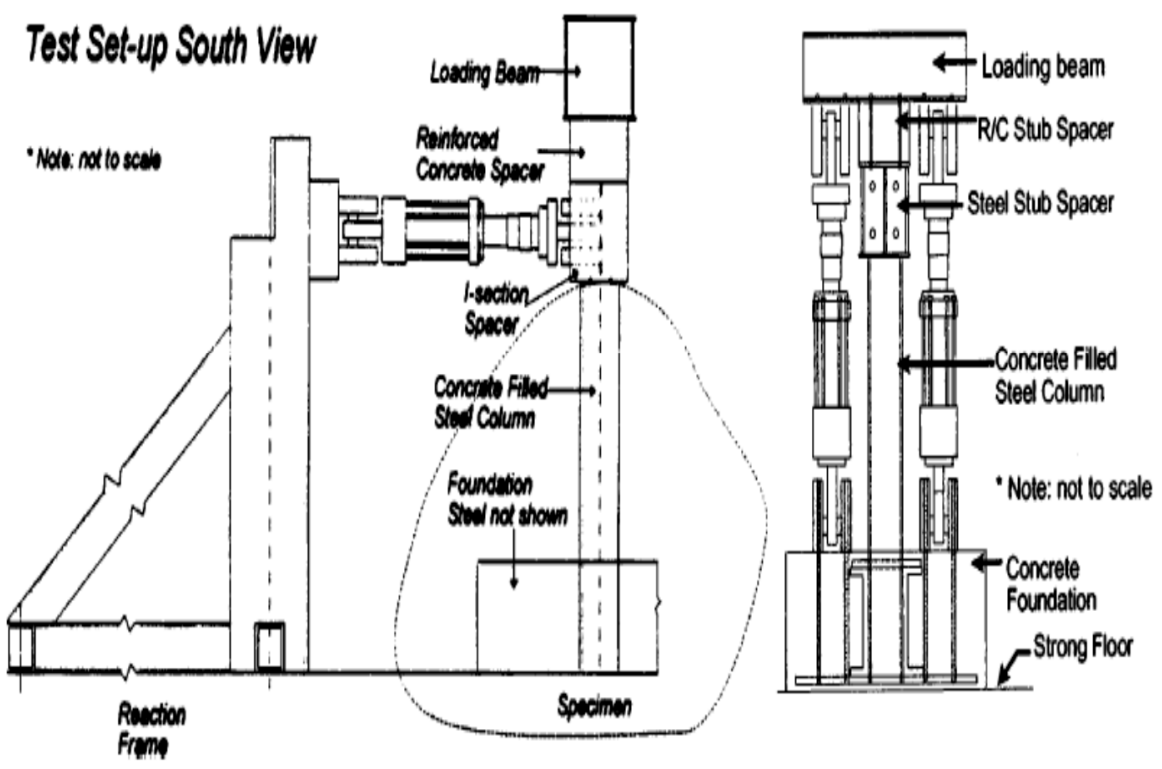

Figure 1. General view of Marson and Bruneau experiment. [2]

In present paper, the sections of square-shaped concrete-filled steel columns under blast load are simulated using non-linear model of finite element. Fracture behavior of concrete filled steel columns with scaled distance will be analyzed equal to one. in this paper, displacement time history curves will be compared with each other based on different scaled distances and ductility and resistance of these sections against explosion will be investigated in the present research.

\section{The effect of increasing temperature on the characteristics of concrete and steel features}

Thermal and mechanical characteristics of steel and concrete are completely different from each other; however by increasing the temperature, the resistance and stiffness of both will be decreased. Stress-strain curves of steel and concrete for normal temperature ( 20 degrees Celsius) have been shown in figures 2 and 3 as T20. For all used sections in this paper, yield stress ( $\left.f_{y}\right)$ is equal to 350 newton per square millimeter, modulus of elasticity $\left(E_{s}\right)$ equal to $21 \times 10^{4}$ newton per Square millimeter, compressive resistance $\left(f_{c}\right)$ equal to 30 newton per square millimeter and strain $\left(\varepsilon_{c}\right)$ equal to 0.0025 have been considered. Stress-strain curve of steel has been drawn affected by increasing the temperature based on regulation of BS EN 1993-1-2 [3] and for concrete based on BS EN 1994-1-2 [4].

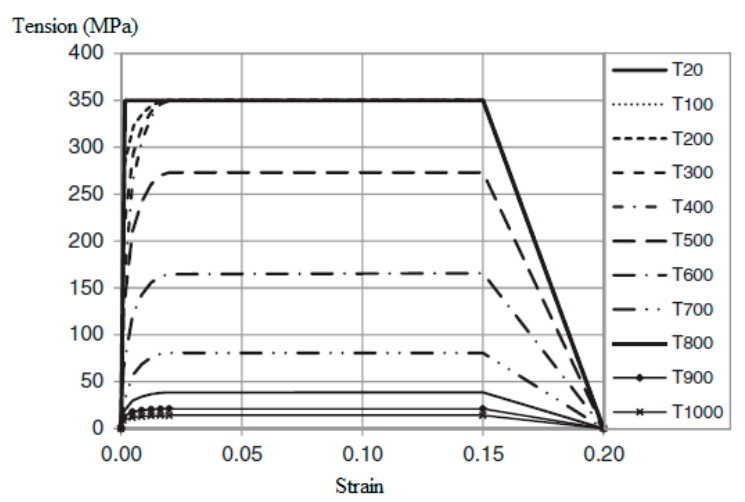

Figure 2. Stress-strain curve of steel affected by increasing the temperature. 


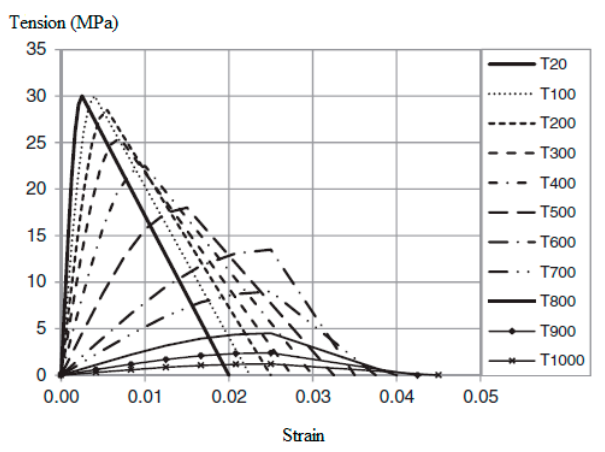

Figure 3. Stress-strain curve of concrete affected by increasing the temperature.

For simulation by ABAQUS [5], the steel will be modeled based on real stress-strain relationship that is obtained from equation 1 and 2.

$$
\begin{aligned}
& \sigma_{\text {true }}=\sigma_{\text {nom }}\left(1+\varepsilon_{\text {nom }}\right) \\
& \varepsilon_{\text {true }}=\ln \left(1+\varepsilon_{\text {nom }}\right)
\end{aligned}
$$

In which, $\varepsilon_{\text {nom }}$ and $\sigma_{\text {nom }}$ are respectively nominal strain and stress of section. The real values of stress and strain of steel have been shown in table 1.

Table 1. Real values of steel strain-stress

\begin{tabular}{cc}
\hline Plastic strain & Real stress (MPa) \\
\hline 0.000 & 300 \\
0.025 & 350 \\
0.100 & 375 \\
0.200 & 394 \\
0.350 & 400 \\
\hline
\end{tabular}

For modeling concrete in plastic area and investigating its destruction, concrete plastic damage model has been used. The values of stress, strain and destructing concrete plastic in tension and compression have been shown in tables 2 and 3.

Table 2. The values of stress, strain and destruction of concrete plastic in tension

\begin{tabular}{ccc}
\hline Destruction in stretch parameter & Cracking strain & Tensile strength (MPa) \\
\hline 0.00 & 0.000000 & 5.3 \\
0.25 & 0.000176 & 5.31 \\
0.99 & 0.001539 & 0.58 \\
\hline
\end{tabular}

Table 3. The values of stress, strain and destruction of concrete plastic in compression

\begin{tabular}{ccc}
\hline Destruction in stretch parameter & Cracking strain & Tensile strength (MPa) \\
\hline 0.000 & 0.000000 & 17.5 \\
0.112 & 0.00038 & 25.7 \\
0.429 & 0.00189 & 34.9 \\
0.466 & 0.00218 & 35 \\
0.701 & 0.00456 & 28 \\
\hline
\end{tabular}




\section{Describing used section}

As it can be seen in figure 4, blast loading happens in determined distance from structure (R). Structure's height is 3 meters and the dimensions of column $500 \times 500$ and the thickness is 10 millimeter.

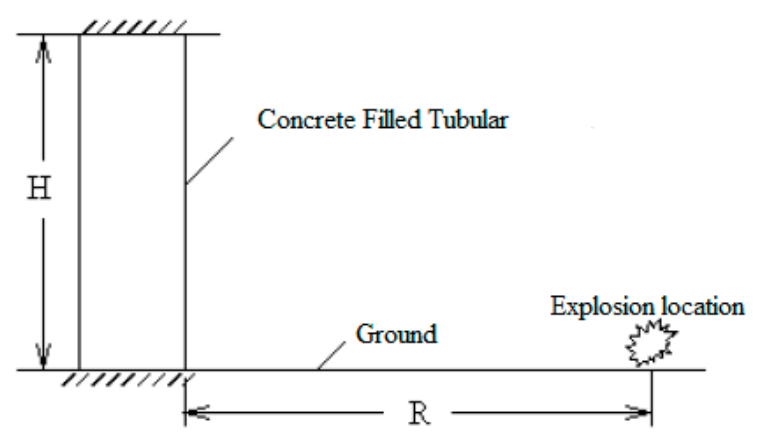

Figure 4. Concrete-filled steel column under blast load.

\section{Numerical simulation by ABAQUS software}

Concrete-filled steel structures will be first modeled in ABAQUS software same as figures 5 and 6.

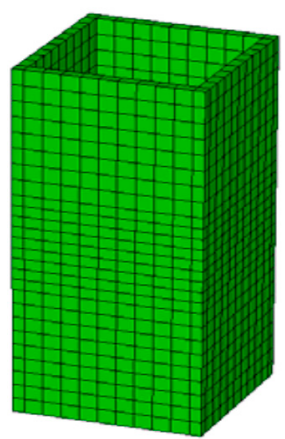

Figure5. Finite element model of steel wall in concrete-filled steel columns.

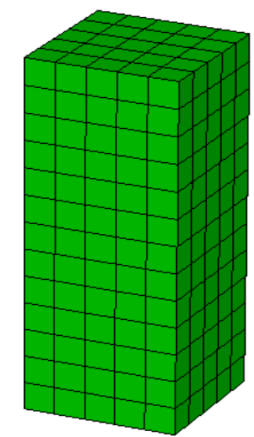

Figure 6. Finite element model of concrete core in concrete-filled steel columns.

Plastic analysis includes three main components of strain-stress curve, yield criterion and hardening law.

Strain-stress curve has been mentioned for structural components in second section. For modeling materials' behavior, Von Mises yield criterion and isotropic hardening law have been used.

Related problems to geometric non-linear analysis are also considered in this model and large deformations method has been used. Analyzing method has been Newton-Raphson software and because of contacting elements between concrete and steel and consideration of contact surfaces friction, non-symmetric Newton-Raphson method has been used. Concrete core is defined by threedimensional element of eight nodes and with three degrees of freedom at each nod using model 
C3D8R. Materials are concrete-type with the capability of cracking in three orthogonal lengths under tensile and fracture under pressure strains as well as plastic deformations.

Steel wall has been defined by C3D8I element that is defined same as C3D8R element with eight nods and three degrees of freedom at each nod and a good agreement with other utilized elements in model. Friction and slip between steel and concrete core is also modeled by surface to surface contacting element. This element is able to transfer pressure toward normal length and shear toward to desired surfaces tangent.

For investigating the behavior after column buckling and passing critical point so that shows decrease in loading capacity without divergence in problem-solving, arc length method is used for solving non-linear equations.

For modeling blast load, existing equations in TM5-1300 regulation [6] have been used. This regulation is extensively used for primary designing the structures under blast loading. Scaled distance is calculated from the third root of different distances to blast load weight that has been shown in equation 3.

$$
z=\sqrt[3]{\frac{R}{W}}
$$

In which $\mathrm{R}$ is distance from blast source and $\mathrm{W}$ is the weight of blast load.

As in figure 7, time-pressure diagram has been shown in which the point of $0.1 \prec p_{s 0} \prec 10$ represent the time of reaching blast wave to structure. After that pressure reaches to its most value that is $p_{s 0}$, then amount of applied pressure is reduced and reaches the amount of environmental pressure $p_{0}$ that till this moment, pressure is in positive phase. Time corresponding to a pressure negative phase with ${ }^{t_{0}^{-}}$and maximum amount of negative pressure has been shown with ${ }^{-}$[7].

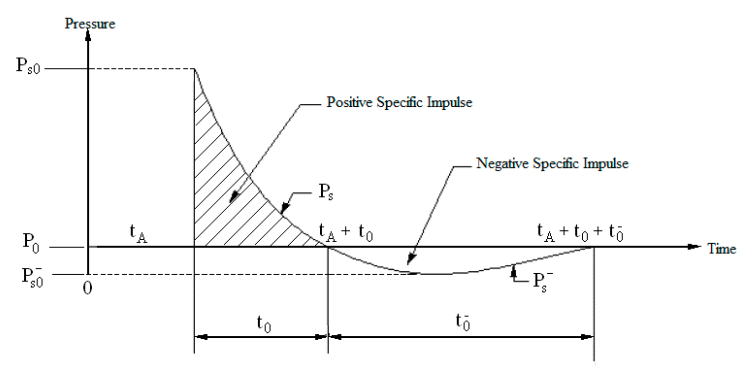

Figure 7. Time-pressure diagram under blast load.

Pressure negative phase compared to the positive one is usually less important for designing. In another word only pressure positive phase is considered for numerical simulation of blast load.

Empirical formula of time-pressure has been shown in equation 4:

$$
P(t)=P_{S 0}\left(1-\frac{t}{t_{0}}\right) \exp \left(\frac{-b t}{t_{0}}\right)
$$

In which, $b$ is a parameter of blast wave

The equation of maximum amount of blast load $p_{s 0}$ was calculated based on scaled distance $\mathrm{z}$ by Board [8] in 1955. This value has been shown in equation (5-a) and (b-5).

$$
\begin{array}{ll}
p_{s 0}=\frac{0.975}{z}+\frac{1.455}{z^{2}}+\frac{5.85}{z^{3}}-0.019 b a r & 0.1 \prec p_{s 0} \prec 10 \\
p_{s 0}=\frac{6.7}{z^{3}}+1 & p_{s 0} \succ 10
\end{array}
$$

On the other hand, Newmark [9] in 1961 proposed another equation for maximum blast load that has been shown in equation 6 . 


$$
p_{s 0}=6784 \frac{W}{R^{3}}+93\left(\frac{W}{R^{3}}\right)^{0.5}
$$

Blast waves are propagated at supersonic speed and ultimately they will collide with structure. After colliding with structure, these waves will be intensified with extra pressure. This subject which has been considered in TM5-1300 regulation, are shown in equations 7 to 11 . The load derived from explosion because of very short time of loading has impact nature and therefore in many cases pressure changes based on time are considered as linear.

$$
\begin{aligned}
& q_{0}=\frac{2.5 p_{s 0}^{2}}{7 p_{s 0}+p_{0}} \\
& p_{R}=p_{s 0}\left[2+\frac{6 p_{s 0}}{7 p_{0}+p_{s 0}}\right] \\
& t_{d}=20.77\left[\frac{\mathrm{W}}{p_{s} 0}\right]^{\frac{1}{3}} \quad p_{s 0} \prec 2 \frac{\mathrm{kg}}{\mathrm{cm}^{2}} \\
& t_{d}=14.35\left[\frac{\mathrm{W}}{p_{s 0}}\right]^{\frac{1}{3}} \quad p_{s 0} \geq 2 \frac{\mathrm{kg}}{\mathrm{cm}^{2}} \\
& t_{b}=10.23\left[\frac{\mathrm{W}}{p_{s} 0}\right]^{\frac{1}{3}} \quad p_{s 0} \prec 70 \frac{\mathrm{kg}}{\mathrm{cm}^{2}} \\
& t_{b}=20.77\left[\frac{\mathrm{W}}{p_{s 0}}\right]^{\frac{1}{3}} \quad p_{s 0} \geq 70 \frac{\mathrm{kg}}{\mathrm{cm}^{2}} \\
& \frac{6 t_{d}, v}{v}\left[1+\frac{6 p_{s 0}}{7 p_{0}}\right]
\end{aligned}
$$

The diagram of pressure changes based on time caused by explosion on different dimensions of structure has been also shown in figures 8, 9 and 10. Pressure changes have been shown for the front face (toward explosion) of structure, side face and roof and for behind explosion.

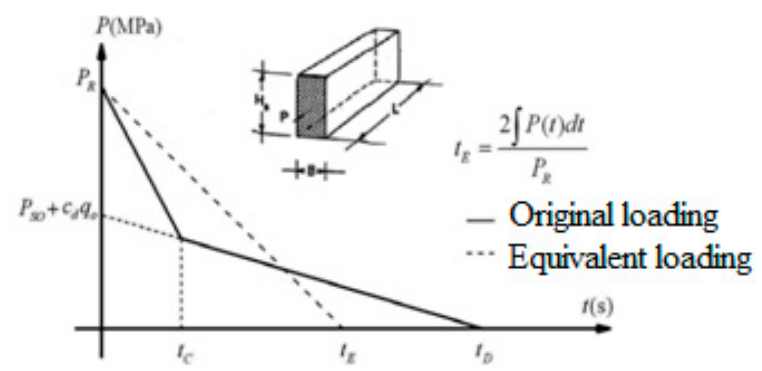

Figure 8. Pressure changes on front face (toward structure) of structure.

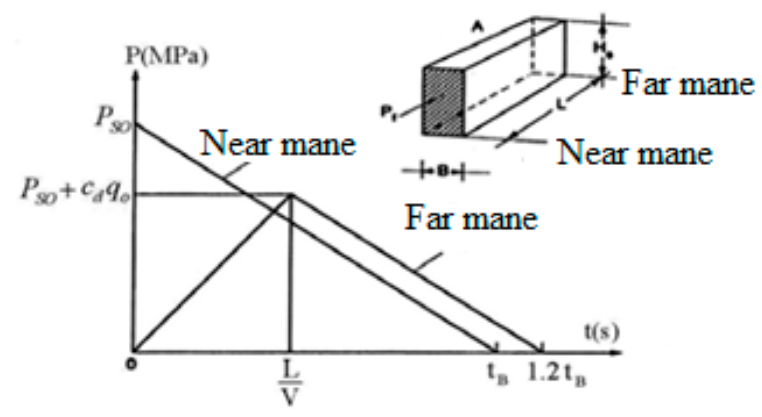

Figure 9. Pressure changes on side faces and roof of structure. 


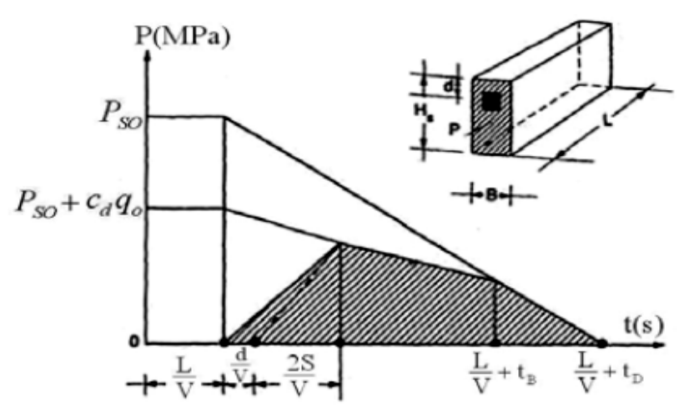

Figure 10. Pressure changes on behind faces of structure.

Distance from the source of explosion ( $R$ ) is 5 meter and scaled distance $(Z)$ is considered with values of $0.7,1$ and 1.3. Blast pressure is considered as load uniformly over the surface of the column. This numerical simulation is implemented in order to evaluate blast responses and the damages of concrete-filled steel columns under blast loads.

\section{Investigating numerical results for $\mathrm{z}=1$}

In figures 11 to 13, displacement values in direction $\mathrm{x}$ and maximum main stress in times 2, 5 and 9 millisecond have been shown. As it can be seen maximum displacement happens in the middle of column. This subject was expected because column has symmetric reliance and was under uniform loading and displacement maximum should naturally happen in the middle of span. Displacement will be increased to 117 millimeter by increasing the time to 9 milliseconds. In terms of stress, it can also be seen that the first tensile damage has happened upside and downside of concrete and main stress maximum become equal to concrete tensile resistance. When the time increases to 9 milliseconds, in middle column concrete, damage and erosion will happen simultaneously. However the ratio of displacement to the height of column is equal to 3.9 percent but it can be concluded that steel section will effectively cause restricting lateral displacement of column and increasing column resistance against explosion.

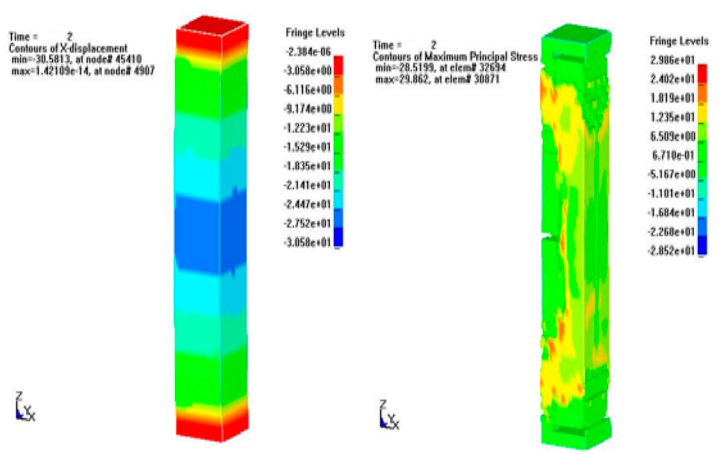

Figure 11. Displacement and stress in 2 milliseconds.

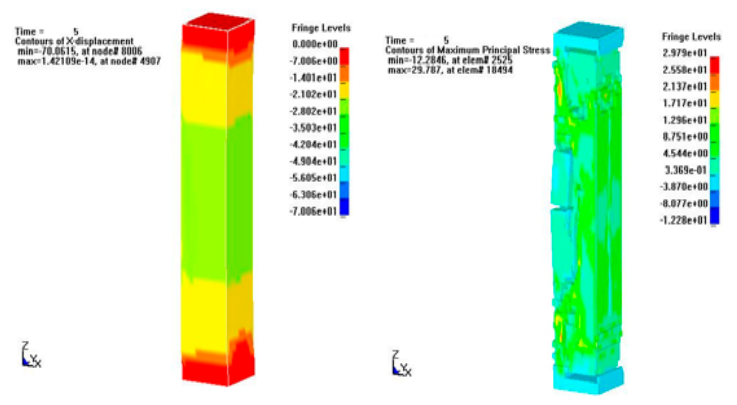

Figure 12. Displacement and stress in 5 milliseconds. 


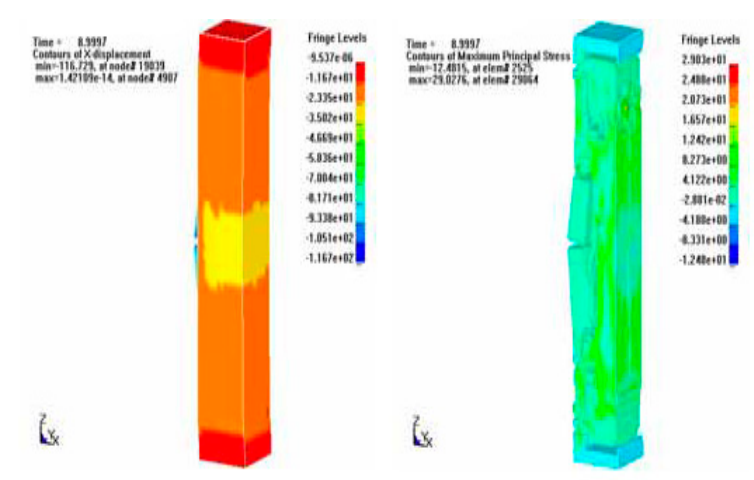

Figure 13. Displacement and stress in 9 milliseconds.

\section{Comparing numerical results for $\mathrm{z}=\mathbf{0 . 7}$ and $\mathrm{z}=\mathbf{1 . 3}$}

In figure 14 the diagram of displacement in direction $x$ column has been shown for scaled distances of 0.7 and 1.3. as it can be seen, maximum displacement of column will decrease by increasing scaled distances.

It can be also observed that unlike ordinary columns where after reaching maximum load, loading capacity will severely decrease and there is no tolerance for large displacement in levels close to maximum load, after reaching maximum load, concrete-filled steel columns have very low decrease in loading capacity and tolerate large displacement well in levels close to maximum load.

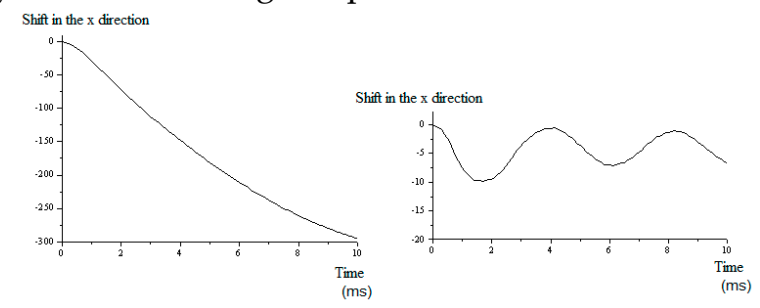

Figure 14. Comparing displacement diagram for $\mathrm{z}=0.7$ and $\mathrm{z}=1.3$

As result it can be said that for modeling the loads caused by explosion, concentrated loads in levels of floors with linear distribution toward time can be used that have adequate accuracy and its error level compared to extensive load with non-linear distribution of time in low-rise buildings is less than 10 percent and in long buildings is about 10 percent. Blast effect on structural components that are closer to the explosion location is absolutely more severe. This means that the most important vulnerable points against blast loads are external structure components and these components are more exposed to damage than other ones. The loads caused by explosion create relatively high shearing power in columns close to blast; this force will be decreased in the columns of next rows. Increasing the number of frame openings doesn't significantly affect created force in the column in first row but it causes reducing general lateral displacement of frame. On the other hand by increasing the floors, created force in columns of low floors of building won't be increased a lot, therefore short buildings are vulnerable toward blast loads out of structure because of high forces caused by blast in them compared to normal designing forces compared by long buildings. Therefore in order to an appropriate design against explosive loads, external structural components should be significantly paid attention. Columns and structural components in first floor are also double important and as a recommendation we can say that designing structure is better to be controlled through eliminating one of external columns in first floor.

\section{Conclusion}

1. Maximum displacement in column will decrease by increasing scaled distances.

2. The columns are the most important factor in determining lateral behavior of moment frames under external blast loads.

3. Steel section will effectively lead to restricting column lateral displacement and increasing column resistance against explosion. 
4. By increasing the dimensions of columns, relative displacement of floors will less change but they won't be decreased necessarily.

5. Increasing the aspects of around columns affect reducing lateral displacement more than increasing the dimensions of inner columns.

6. When the time increases up to 9 milliseconds, in the middle concrete of column, damage and erosion will occur simultaneously.

\section{References}

1. Fujikura, S. Bruneau, M. and Lopez-Garcia, D, 2008, "Cyclic Testing of Concrete-Filled Circular Steel Bridge Piers Having Encased Fixed-Base Detail," ASCE Journal of Bridge Engineering, Vol. 13, No. 6, pp. 586-594.

2. Marson, J. and Bruneau, M, 2004, "Cyclic Testing of Concrete-Filled Circular Steel Bridge Piers Having Encased Fixed-Base Detail," ASCE Journal of Bridge Engineering, Vol. 9, No. 1, pp. 14-23.

3. BS EN 1993-1-2, “Eurocode 3: design of steel structures, Part 1.2: General rules structural fire design", London: British Standards Institution; 2005.

4. EN 1994-1-2, 2005, “ Eurocode 4: design of composite steel and concrete structures. Part 1.2: general rules-structural fire design", London, British Standards Institution

5. ABAQUS standard user's manual, vols. 1-3. USA: Hibbitt, Karlsson and Sorensen, Inc; 2008. version 6.8-1.

6. TM5-1300, "Structures to resist the effects of accidental explosions", US Army, USA, 1990.

7. Bing ,L., Tso-Chien, P. and Anand., N., 2008, “ A case study of the effect of cladding panels on the response of reinforced concrete frames subjected to distant blast loadings", Elsevier, Singapore.

8. Brode, H.L., 1955, “ Numerical solutions of spherical blast waves", J. Applied Phys., 26: 766766. DOI: $10.1063 / 1.1722085$.

9. Newmark, N.M., 1961, " Protective Construction Review Guide-hardening", 1st Edn., Defense Technical Information Center, pp: 324.

(C) 2016 by the authors; licensee Preprints, Basel, Switzerland. This article is an open access article distributed under the terms and conditions of the Creative Commons by Attribution (CC-BY) license (http://creativecommons.org/licenses/by/4.0/). 